\title{
Our change of Co-Editor-in-Chief and the journal's prospects
}

\author{
Yong S. Chung ${ }^{1} \cdot$ Jonathan M. Samet ${ }^{2} \cdot$ Frank J. Kelly $^{3}$ \\ Received: 1 October 2019 / Accepted: 1 October 2019/Published online: 16 October 2019 \\ (C) Springer Nature B.V. 2019
}

Air pollution has been a problem for centuries, reflecting the burning of fuels for heating and cooking and industrial activities. Globally, pollution has been dynamic with successful management taking place in higher-income countries, but worsening quickly in many low- and middle-income countries undergoing rapid industrialization, particularly China and India. As a result, these countries are experiencing high levels of air pollution on a frequent basis, creating large air pollution masses that circulate globally, and also becoming major contributors to greenhouse gasses. Consequently, the burden of premature mortality and morbidity attributable to air pollution is large and air pollution is now a leading contributor to poor health in most industrialized countries. And while climate change has been recognized as an emerging problem for decades, the urgency of action is clear as predictions as to its consequences have been realized. Climate change and global warming have been documented from low latitudes to polar environments. The health consequences of climate change

Yong S. Chung

chungys22@gmail.com

Jonathan M. Samet

JON.SAMET@UCDENVER.EDU

Frank J. Kelly

frank.kelly@kcl.ac.uk

1 Korea Center for Atmospheric Environment Research, 304 Koonghyon, Khangnae, Cheongju, Choongbook 28177, Korea

2 Colorado School of Public Health, Aurora, CO, USA

3 Department of Analytical, Environmental and Forensic Sciences, King's College London, Franklin-Wilkins Building, Stamford Street, London SE1 9NH, UK will occur through direct and indirect pathways that include worsening air pollution.

This nexus of air pollution, greenhouse gasses, and climate change was the motivation for launching a new international journal. One purpose was to highlight these interactions with the goal of motivating action globally by publishing scientific research that covered the full global spectrum of the pollution problem. The journal's history dates to 2005 when Yong S Chung met with Paul Roos, then Editorial Director of the Environmental Sciences publication program of Springer in the Netherlands. Roos supported the proposal for a new journal and Tamara Welschot, then Senior Publishing Editor of Environmental Sciences with Springer carried out major market surveys to assess the potential of widespread subscriptions including libraries in many countries. After three years of preparations with Springer, we announced the launch of the new international journal, Air Quality, Atmosphere \& Health (AQAH) in 2008. Jonathan M Samet joined Yong $\mathrm{S}$ Chung as the founding Editors-in-Chief. Together, they had the breadth of expertise needed to launch this international, multidisciplinary journal in combination with the team of Associate Editors.

Since its launch, the journal has shown consistent and strong growth: in June 2008, we published the first issue of Volume 1, and continued to publish quarterly issues until Volume 7 in 2014, when we moved to six issues per year, to ten issues in 2017 , and to 12 issues as of 2019. In 2008, we began with 235 pages, and this year, the journal is anticipated to reach 1480 pages. That our journal also resonated well with its relevant communities is also shown through the awarding of an Impact Factor in 2012 (3.184 in 2017 and 2.297 in 2018), only four years after the journal's launch. Our authors and co-authors are from all five continents in- 
cluding 91 countries ${ }^{1}$. For the abatement and monitoring of air quality and greenhouse gasses, we do encourage quality papers from developing countries and we conduct peer reviews on all submissions. Presently, the rate of acceptance from all submissions is about $22 \%$.

These achievements would not be possible without the support of our Associate Editors and Editorial Board members, and we are grateful to them. In addition, our authors, reviewers, and readers have been consistently supportive in submitting high-quality papers, in generously agreeing to review papers, and to reading and citing papers in AQAH. We are indebted to our friends on five continents for supporting the journal as it has risen to have wide international recognition.

After 12 years of exceptional editorial service, Prof. Samet is retiring from his position as Co-Editor-in-Chief to be replaced by Prof. Frank J Kelly of King's College London. We thank Jonathan for his contributions as a founding Editor-in-Chief and for the editorial vision he helped to form. Prof. Frank J Kelly brings broad expertise in the health consequences of air pollution, drawing on his work in environmental toxicology and his broad work in integrating scientific evidence on air pollution to protect public health. His more than 400 publications cover a broad range of environmental health topics. We look forward to the new insights that he will bring.
We would like to sincerely thank Jonathan for his productive work and wish him happy days ahead. We also warmly welcome Frank to the AQAH world! A word from him:

Thank you for the warm welcome. As we enter this crucial period of air quality research and policy development and implementation, I am excited by the opportunity to be part of AQAH's contribution to this truly international activity. Of course, following in the footsteps of Prof. Samet will be no easy task but my goal is to contribute to the ongoing growth in quality of the Journal and to ensure it is seen as a platform for scientific excellence. London has been a focus for air quality highs and lows in the past and the knowledge gained through these experiences should hold me in good stead to tackle the challenges, and opportunities ahead. I look forward to the next few years as Co-Editor-in-Chief of AQAH, with a commitment to lead the Journal towards its stated goals, working closely with you, the editorial board and the publisher, Springer Nature.

Publisher's note Springer Nature remains neutral with regard to jurisdictional claims in published maps and institutional affiliations.

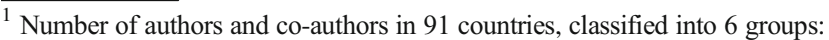

Group I (above 19): USA 230, China 79, India 59, UK 48, Korea 43, Canada 39, Portugal 38, Italy 35, Greece 27, Australia 25, France 23, Spain 23, Japan 23, Germany 22, Poland 20 (15 countries)

Group II (above 6): Iran 18, Turkey 17, Malaysia 16, Brazil 15, Norway 14, Finland 11, Mexico 10, Belgium 10, Saudi Arabia 10, Macedonia 10 , Thailand 10 , Switzerland 9 , Chile 9 , Netherlands 8 , Servia 8 , Bangladesh 8, Brazil 7, Vietnam 7 (18 countries)

Group III (above 3): Austria 6, Taiwan 6, Hong Kong 6, Columbia 6, Russia 5, South Africa 5, Israel 5, Pakistan 5, Czech 4, New Zealand 4, Cyprus 4, UAE 4, Slovenia 4, Hungary 4, Croatia 4, Algeria 4 (16 countries)

Group IV (each 3): Sweden, Ireland, Argentina, Bulgaria, Singapore, Kazakhstan, Egypt, Mongolia, Lebanon, Jordan (10 countries) Group V (each 2): Denmark, Luxembourg, Peru, Nigeria, Cyprus, Slovakia, Lithuania, Albania, Oman, Morocco, Palestine (11 countries) Group VI (each 1): Jamaica, Nepal, Kyrgyz, Congo, Cameron, Albania, Laos, Bulgaria, North Korea, Ethiopia, Cuba, Nigeria, Uzbekistan, Kuwait, Suriname, Tanzania, Estonia, Scotland, Romania, Qatar, Slovenia (21 countries) 